\title{
The Impact of the Peer-Tutoring Online Discussion (POD) Class Model during the COVID-19 Pandemic
}

\author{
Taeyoung Kim ${ }^{1}$, Sung Kyung Chu ${ }^{1}$, So Yeon Byeon ${ }^{1}$, Hae Gyung Yoon ${ }^{2}$, Yongha Kim ${ }^{3}$ \& Hyunmyung Jo ${ }^{4}$ \\ ${ }^{1}$ Dignitas Institute for Liberal Education, Dong-eui University, Busan, South Korea \\ ${ }^{2}$ Division of Basic Sciences, Dong-eui University, Busan, South Korea \\ ${ }^{3}$ Division of Literature, Dong-eui University, Busan, South Korea \\ ${ }^{4}$ Graduate School of Education, University at Buffalo, Buffalo, USA \\ Correspondence: Hyunmyung Jo, Graduate School of Education, University at Buffalo, Buffalo, New York, USA.
}

Received: May 29, 2021

doi:10.5430/ijhe.v10n7p53
Accepted: July 12, 2021

Online Published: July 13, 2021

\begin{abstract}
The rapid spread of online classes in higher education during and after the COVID-19 pandemic has created a growing need for research that explores the issue of student disengagement in online courses. In this regard, the present study suggests a Peer-Tutoring Online Discussion (POD) class model to increase student engagement in online courses among undergraduate students with diverse sociocultural backgrounds and college majors. The study also examines the impact of the POD approach by exploring the experiences of undergraduate students who took online liberal arts courses that employed the POD model during the 2020 spring semester. Qualitative analysis of discussion data from students indicates that the POD class model includes characteristics that can be especially significant in the context of the COVID-19 pandemic, such as opportunities for relationship-building, self-directed learning based on establishing a rapport, and discussion management that considers time limits.
\end{abstract}

Keywords: online course, student engagement, self-directed learning, peer-tutoring

\section{Introduction}

As the demand increases for strengthening students' basic learning abilities and competence at the higher-education level, peer-tutoring programs that effectively support learning activities have attracted a great deal of attention (Arco-Tirado, Fernández-Martín, \& Hervás-Torres, 2020; De Backer, Van Keer, \& Valcke, 2015). Peer-tutoring programs are a structured form of peer learning in which students take on the roles of tutor and tutee (Thurston, Cockerill, \& Chiang, 2021), and have been widely used to reduce school maladjustment, decrease attrition rates, and improve the quality of learning environment. There is a variety of peer-assisted techniques among subject areas, which are primarily divided into two types of peer-tutoring programs. The first type is a ClassWide Peer Tutoring (CWPT) program, which allows a teacher to organize students into tutor-tutee pairs, with competition between pairs (Greenwood, 1997). The other type of program offers peer tutoring sessions to train selected students to be tutors in the class (Arco-Tirado, Fernández-Martín, \& Fernández-Balboa, 2011). The peer tutoring program addressed in this study is closer to the former, and will be detailed further in the Method section below.

Recently, owing to the rapid spread of online higher education classes during the COVID-19 pandemic, a need has emerged for research exploring the issue of student engagement in online courses from the perspective of peer tutoring (Ala, Yang, \& Ala, 2021; Cavus, Sani, Haruna, \& Lawan, 2021; Mendoza \& Kerl, 2021). Given the significant impact of peer-tutoring programs on students' academic achievement and motivational gains, including self-esteem and self-confidence (Goodlad, 1998; Parkin \& McKeganey, 2000), it is particularly expected that the peer-tutoring approach can provide a new method through which the issue of student disengagement in online coursework can be improved.

\section{Literature Review}

Despite the practical advantages of online coursework as an alternative to traditional face-to-face learning, scholars have noted the issue of student disengagement as a weakness (Octaberlina \& Muslimin, 2020; Patterson \& McFadden, 2009; Willging \& Johnson, 2019). For example, using archival data collected between 2004 and 2009 for students enrolled at a public university located in the southwestern United States, Atchley, Wingenbach, and Akers 
(2013) reported that course completion rates among students enrolled in online courses were lower, and that the distribution of their academic performance tended to be more polarized, compared to their counterparts enrolled in traditional courses. More specifically, while the course completion rate among students enrolled in traditional courses was $95.6 \%$, it was lower for their counterparts enrolled in online courses, at $93.3 \%$. Regarding grade distribution, students enrolled in online courses had higher percentages of As (34.6\%) and Fs (10.7\%), compared to those enrolled in traditional courses, of which $31.3 \%$ and $8.2 \%$ had As and Fs, respectively. Similarly, drawing on a dataset of students who took either an online or face-to-face course between 2004 and 2010 at a large urban community college in the northeastern United States, Wladis, Conway, and Hachey (2017) indicated that the gap in course completion rates between online and face-to-face courses was larger in upper-level than lower-level courses. According to their analysis, while the successful course completion rates for students enrolled in lower-level courses were $49.9 \%$ for online classes and $42.2 \%$ for face-to-face classes, their counterparts enrolled in upper-level courses had successful completion rates of $73.7 \%$ and $77.8 \%$ for online and face-to-face classes, respectively.

In addition, Murphy and Stewart (2017) investigated the issue of unsuccessful course completion in an online science course based on data collected between 2004 and 2014 from undergraduate students at a public university in the southern United States. They reported that, compared to face-to-face courses, higher rates for student re-enrollment in the course and early student disengagement in the online course were closely associated with a lower course completion rate. Moreover, in a mixed-methods case study on two Massive Online Open Courses (MOOCs) at two universities, Comer, Baker, and Wang (2015) indicated that negativity in MOOCs could impact findings on student disengagement and instructor burnout, and argued that considering precautions that could be taken against such negativity may help improve the quality of the academic environment in online courses. In addition, researchers have demonstrated various factors that work against student engagement in online learning, such as students emphasizing other priorities (Moore, Bartkovich, Fetzner, \& Ison, 2003), technical difficulties (Gemmell \& Harrison, 2017; Jaggars, 2014; Sitzmann, Ely, Bell, \& Bauer, 2010), and students' lack of self-regulatory capabilities (Cho \& Heron, 2015; Lee \& Choi, 2011; Lee, Choi, \& Kim, 2013).

Given the growing importance of online learning during and after the COVID-19 pandemic, scholars and policymakers have viewed the issue of student disengagement in online coursework as an urgent problem. For instance, based on a Strengths, Weaknesses, Opportunities, and Challenges (SWOC) analysis, Dhawan (2020) argued that, after the deadly pandemic, online learning and teaching became a necessity rather than an option. Similarly, Adedoyin and Soykan (2020) emphasized that the crisis-response migration to online coursework during the pandemic should be understood from the perspective of an emergency situation, and could not serve as an ideal and efficient transformation to an online education system. Importantly, the construction of an effective online teaching and learning system during the pandemic has become a central issue in the field of education today.

Thus, there is a significant need to consider the supplementary effects of peer tutoring programs on online learning during this era. Furthermore, while previous research on peer-tutoring programs has predominantly focused on delivering knowledge and improving achievement (Alegre, Moliner, Maroto, \& Lorenzo-Valentin, 2020; Roscoe \& Chi, 2007; Thurston et al., 2020; Xu, Hartman, Uribe, \& Mencke, 2001), researchers have neglected to investigate the interaction between a peer tutor and peer tutees during class discussion. By considering these situations comprehensively, the present study aimed to explore a class model utilizing a peer-tutoring program, based on empirical evidence collected from undergraduate students who successfully completed online discussion courses during the COVID-19 pandemic, and to suggest a Peer-Tutoring Online Discussion (POD) class model to increase online course engagement among undergraduate students with diverse sociocultural backgrounds and college majors.

\section{Method}

This study used empirical data from two sample groups of undergraduate students who participated in online liberal arts courses during the COVID-19 pandemic in South Korea (hereafter, Korea). Using a qualitative method, the present study collected and analyzed data from recorded online classes over an entire semester. The details will be explained in the following data collection and data analysis sections.

\subsection{Context of the Case}

Korea is well known for having a high level of educational attainment in relation to higher education. For example, in $2019,70 \%$ of Koreans aged between 25-34 years had a tertiary education degree, which is more than $20 \%$ higher than comparable attainment rates in the United States or the OECD average (OECD, 2020). In 2020, there were 191 four-year universities (35 public and 156 private) and 148 other types of postsecondary institutions in Korea (KOSIS, 2020). Like many other cases worldwide, universities in Korea have been required to offer online courses since the outbreak of the COVID-19 pandemic. Given the aforementioned obstacles in the process of online coursework, the 
College of Liberal Studies (CLS) at Delta University (pseudonym), a private university located in the southern part of Korea, has provided online liberal arts courses based on a peer-tutoring approach for student engagement since the 2020 spring semester.

The CLS offers two online discussion courses on issues of posthuman and convergent thinking. Each course includes 18 teams of 5 students per team. Most classes are conducted only by student teams, and students record their discussions and submit them as video files for the CLS to review. Specifically, the courses consist of three phases: preparation, discussion, and feedback. First, in the preparation phase, the CLS provides orientation materials for tutor selection and discussion guidelines. Students then review the orientation materials, select a peer tutor and make rules for their team, and prepare paperwork, including a tutor-tutee pledge. Second, in the discussion phase, students discuss their own topics and keep a log for each class, and the CLS provides three official opportunities per team for faculty-student interactions. Third, in the feedback phase, after each meeting, the CLS examines both video-recorded discussions and student logs, and students consider the feedback from the CLS for their discussion and final outcomes. At the end of the course, all teams participate in an open online meeting and present their result of discussions. In addition, the CLS provides students with video clips of lectures as basic references during the semester, and students can receive a grade of either pass or fail. The POD class model is explained in Table 1.

Table 1. The Peer-Tutoring Online Discussion Class Model

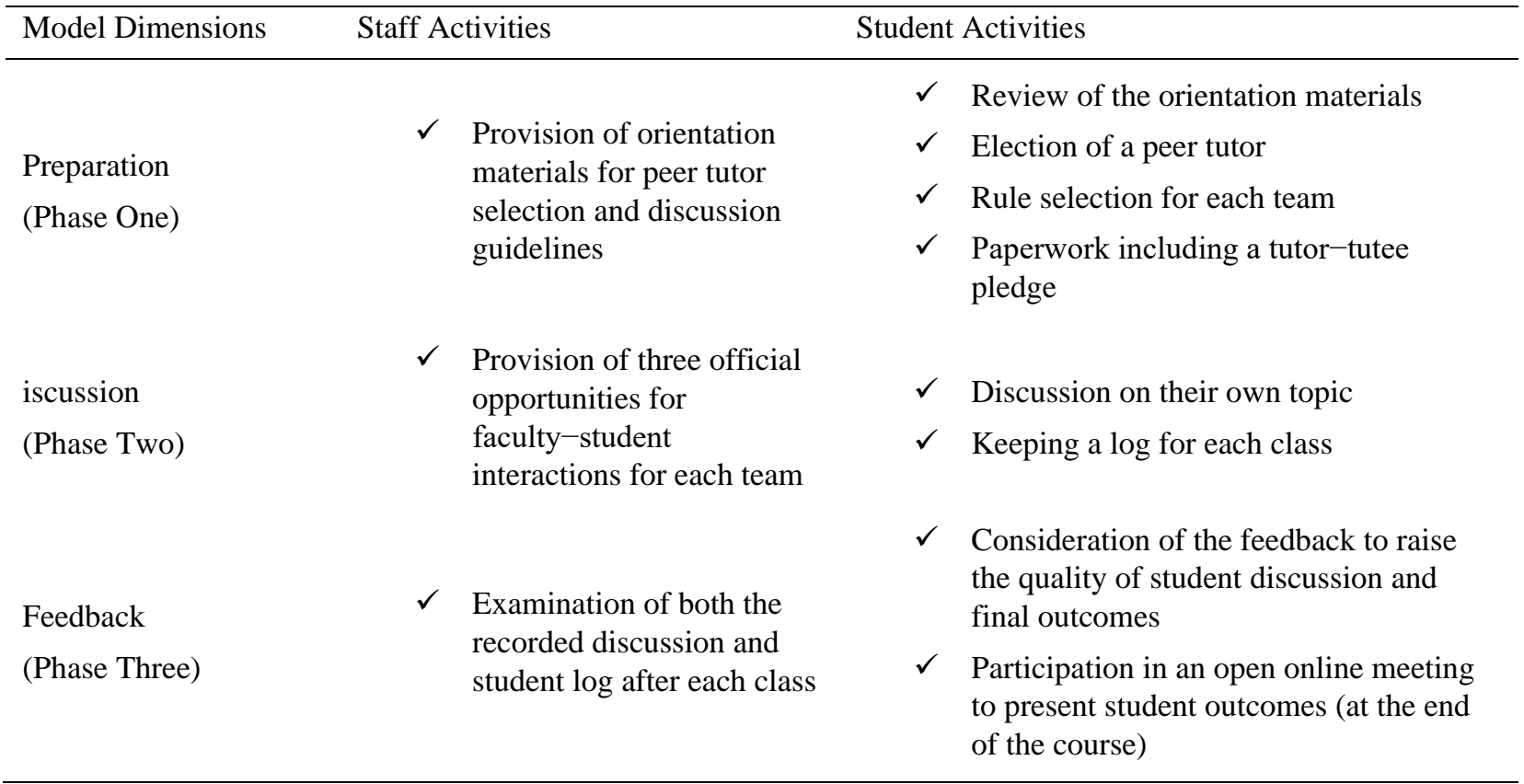

\subsection{Data Collection}

In this study, data were collected through a two-step process. First, among 180 students in two courses, the CLS created teams to ensure that internal diversity could be maintained in each team as much as possible. Background characteristics of this cohort are shown in Table 2. Second, on the basis of student outcomes, including final presentations, video-recorded discussions, and student logs, two teams were selected (one from each course) to provide the data examined in the current study. Faculty members selected one team who engaged the most in each course. Background characteristics of the two teams in this work are presented in Table 3. The current study used video-recorded discussion data from these two sample groups of undergraduate students who participated in the courses during the 2020 spring semester. 
Table 2. Distribution of Respondents' Characteristics

\begin{tabular}{|c|c|c|c|}
\hline & & Number & Percentage \\
\hline \multirow{2}{*}{ Gender } & Male & 65 & 43.3 \\
\hline & Female & 85 & 56.7 \\
\hline \multirow{3}{*}{ Major } & Natural \& Engineering Science & 84 & 56.0 \\
\hline & Humanities \& Social Science & 55 & 36.7 \\
\hline & Arts \& Sports & 11 & 7.3 \\
\hline \multirow{3}{*}{ Class Year ${ }^{\mathrm{a}}$} & Sophomore & 41 & 27.3 \\
\hline & Junior & 51 & 34.0 \\
\hline & Senior & 58 & 38.7 \\
\hline
\end{tabular}

a. These courses are for students in their sophomore year and higher.

\subsection{Data Analysis}

Each course consisted of 16 online classes, and the discussion data from all classes were qualitatively analyzed. In this iterative process, manual coding was conducted twice before digital coding commenced, by focusing on tutor-tutee interactions and their problem-solving strategies. The entire dataset was then reviewed using ATLAS.ti 8 software, and digital coding ultimately produced 135 codes. The codes included the following:

- Tutor activities (e.g., clarification of arguments, requests for work division, suggestions for modified opinions, encouragement, questions for deeper discussion)

- Tutee activities (e.g., problem-posing, contributing to the debate, presiding over the discourse, encouragement, suggestions for deeper discussion)

- Opinions based on knowledge in the field related to a student's own major

- Problem-solving strategies (e.g., acceptance of a tutee's suggestion, acceptance of a tutor's suggestion, deduction of a solution through discussion, and contact with instructors)

Following the coding process, analytic memos were developed to identify emergent themes. The approach based on analytic memos enabled the researchers to identify emergent themes, such as relationship-building, self-directed learning, and discussion management, in terms of student engagement.

Table 3. Characteristics of Research Participants

\begin{tabular}{|c|c|c|c|c|c|c|c|c|c|}
\hline & & $\begin{array}{l}\text { Course } \\
\text { Post-Hu }\end{array}$ & $\begin{array}{l}\text { Title: } \\
\text { lan }\end{array}$ & anding & & & Course & $\begin{array}{l}\text { Title: The Convers } \\
\text { and Practical Act }\end{array}$ & $\begin{array}{l}\text { nce Mindset } \\
\text { ons }\end{array}$ \\
\hline & & Gender & Field of Major & Class Year & & & Gender & Field of Major & Class Year \\
\hline S1 & (Tutor) & Female & $\begin{array}{l}\text { Police } \\
\text { Administration }\end{array}$ & Junior & S6 & (Tutor) & Male & $\begin{array}{l}\text { Environmental } \\
\text { Engineering }\end{array}$ & Senior \\
\hline S2 & (Tutee) & Female & Service Industry & Junior & S7 & (Tutee) & Female & $\begin{array}{l}\text { Fire Service } \\
\text { Administration }\end{array}$ & Junior \\
\hline S3 & (Tutee) & Female & $\begin{array}{l}\text { Early Childhood } \\
\text { Education }\end{array}$ & Senior & S8 & (Tutee) & Male & Business & Sophomore \\
\hline S4 & (Tutee) & Female & $\begin{array}{l}\text { International } \\
\text { Trade }\end{array}$ & Sophomore & S9 & (Tutee) & Male & $\begin{array}{l}\text { Finance and } \\
\text { Real Estate }\end{array}$ & Sophomore \\
\hline S5 & (Tutee) & Male & $\begin{array}{l}\text { Metallurgical } \\
\text { Engineering }\end{array}$ & Senior & $\mathrm{S} 10$ & (Tutee) & Male & $\begin{array}{l}\text { Robotics } \\
\text { Technology }\end{array}$ & Senior \\
\hline
\end{tabular}

\section{Findings}

\subsection{Opportunities for Relationship-Building}

Each team comprised five undergraduate students, who were able to build a rapport with each other, contrary to what previous studies have posited regarding online classes (Ali \& Smith, 2015; Kaufmann \& Vallade, 2020). As five 
students in each team attended the online classes without an instructor and discussed their research questions only among themselves, for the most part, the atmosphere in the online classes was free and casual, rather than formal and rigid. Specifically, at the beginning and end of each class, students shared their own experiences and everyday lives with each other. For example, students expressed their thoughts on the impact of the COVID-19 pandemic on their lives and their post-pandemic wishes as follows:

S1: Where do you want to go, if you can do it after the pandemic?

S2: The ocean!

S1: Me, too!! The ocean!!

S2: I wanna... I wanna go somewhere open.

$[\ldots]$

S4: I also want to go abroad. Actually, I planned to go to Macao, but I couldn't make it because of the pandemic. I had to get a refund.

S1: Really? Oh, my!!

$[\ldots]$

S5: Me, too. I also wanted to visit Europe, but because of the pandemic, my plans have been thwarted. So, because this is my last year, I thought that it's my last chance for a trip.

S1: So, did you make plans and save money to go on a trip?

S5: I was making plans, but I had to cancel them.

This conversation illustrates that the POD class served as an important medium for communication among students in the age of the "new normal." In particular, through the online classes, students were able to recommend dinner menus, suggest movies or dramas, provide tips for obtaining a part-time job, and share their difficulties with coursework in their own majors. These activities served to establish a rapport among team members, thereby encouraging them to collaborate with each other toward a shared goal of student engagement.

\subsection{Self-Directed Learning Based on Rapport}

Discussions among the sample groups also revealed that collaborative circumstances based on the rapport among students in each team could have a meaningful effect on the peer-tutoring program, in that a peer tutor might have difficulties dealing with the problem of student disengagement from peer tutees. In particular, given that a peer tutor would not be chosen for his or her intellectual capacity in a liberal arts discussion course comprised of students from different fields of studies, the cooperative interactions between a peer tutor and peer tutees significantly contributed to students' self-directed learning in the POD classes. Tutees supported their tutor by helping out and actively responding to their tutor's suggestions. For instance, the following scenes show that tutees tried to share the role of their tutor and encourage other tutees, when students started to become disengaged during the lengthy meeting:

S8: Excuse me, S10?

S10: Yeah?

S8: With regard to the inclusion of a video clip on the backdraft [phenomenon]...

S10: OK.

S8: I mean, with regard to the PowerPoint slide. How I can say this? You didn’t put it on the slide. Is it because you couldn't find any video clips? Or, you couldn't find how to do it?

S10: Ah, you're right. I couldn't do it with my laptop.

S8: Oh, I see.

S10: Can you do this, and upload it after that? I have an address [of the webpage for the video clip].

S8: OK. Give me a few minutes, please.

* $* \begin{array}{lllll}* & * & * & * & *\end{array}$

S1: Let's not be too greedy about winning the final presentation.

S2: Why? We can win the victory! Haha.

S1: Haha. That would be nice, if we can do that. 
S4: Ah...

S2: Yeah, that's what we are doing now. So, let's work hard and get good results!

These collaborative interactions between a peer tutor and peer tutees led students to provide positive feedback to each other and encouraged them to more actively participate in the coursework. Furthermore, the cooperation among students enabled them to raise the quality of the interactions between students and instructors. As noted above, during the coursework process, students were offered three opportunities to interact with their instructor. Knowing that the interactions were limited, students hoped to receive positive feedback from their instructor and struggled to effectively use the opportunities on the basis of their collaborative interactions, as illustrated below:

S2: Let's talk about how we will have a talk with the instructor [next week].

S1: Ah, right.

S4: Yes.

$[\ldots]$

S2: Each student may need to talk for 10 minutes. Right? Maybe 5 minutes, at least.

$[\ldots]$

S4: No. I guess the instructor may need some time to speak.

$[\ldots]$

S1: OK. Then, let's try this. So, now we investigated three topics. So, when a student talks about what he or she investigated, each student will give a comment in a positive or negative way.

Here, it can be seen that, since the schedule for each interaction with their instructor was announced, students could and did prepare for the meetings themselves in advance to maximize the effect. Accordingly, despite the limited number, students were able to actively participate in the discussion to create opportunities for significant interactions with their instructor.

\subsection{Discussion Management Considering Time Limits}

Although there were no authoritative moderators in the POD classes, narratives from the sample groups indicated that participants collaborated for efficient and effective discussion management. For example, in the following scene, students recognized that they had spent enough time discussing related issues on potential research topics, and called attention to the selection of a research topic for their own team:

S7: So, we've spent almost one hour already [...]

S8: OK, let's move on.

S6: Yeah, this is a team project.

S7: Right. We need to choose a topic for our team now. I think we should fix it quickly.

S6: Yeah. But, robots... It sounds a little bit surreal. I mean... It would be better to think about the automated system. It's also a kind of robot.

$[\ldots]$

S8: Ah, but, as you know, if we plan to investigate robots with regard to fire accidents, [we can know that] the production of the robot itself is not surreal. It can be customized. It's possible. But, the process of production is quite complicated. So, the fact that you have an idea doesn't mean that you can actually make it. Because it's complicated. [...] So, if we want to present this topic, we need to consider all of these conditions.

Since they had their course syllabus and were required to log their activities in every class, participants exerted themselves to achieve the goal of each online class by considering the time limit. Specifically, there were three main time management strategies used during discussions. First, at the beginning of class, students identified their goals and plans for the day. Second, students checked the remaining time and tasks during class. Third, at the end of each class, students clarified their assignments for the next class and decided whether they would have an additional meeting to complete any unfinished tasks. When faced with a difficult obstacle, the students managed their time by deciding to ask their instructor questions later, rather than spending a long time on the problem. As a result, participants voluntarily strived to efficiently and effectively manage the POD classes, to avoid extra work and successfully attain their academic goals. 


\section{Discussion}

This study provides empirical evidence on the advantages of the POD class model by exploring the experiences of undergraduate students who took one semester of an online liberal arts course designed using the POD approach. Specifically, the analysis showed that the POD course included characteristics that are especially significant in the context of the COVID-19 pandemic. In particular, it contributed to building ties among students by allowing them to share their everyday lives during the online meetings. Given the positive effect of intimate social communication on reducing psychological burden (Pevalin \& Goldberg, 2003; Tew et al., 2012), establishing a rapport among students can be significant for maintaining and encouraging the appropriate level of student engagement.

Regarding self-directed learning, the rapport among students also serves to form collaborative circumstances that result in supportive interactions between a peer tutor and peer tutees through the coursework. Based on the collaborative circumstances, students are able to participate in the class actively and intentionally to achieve academic success, and voluntarily prepare in advance to enhance the effects of meetings with their instructors. In addition, the submission of class records and logs also leads students to consider more efficient and effective discussion management, to meet their target during each class within the time limit provided and avoid extra work.

Thus, the POD model approach provides implications for broader knowledge related to online coursework in more diverse settings. Contrary to findings in previous studies on online courses, the POD classes in this study were shown to actualize positive possibilities, such as relationship-building, self-directed learning, and student engagement. However, this study also has several limitations. First, this study utilized data from two sample groups that were recommended by faculty members to serve as exemplary cases. Thus, further research is needed to examine example cases of both "success" and "failure" together. Second, given that the present study was based on data from discussion courses in the liberal arts field, for the general application of these findings, it will be necessary to examine data from courses using a traditional format that requires more professional knowledge and results in hierarchical evaluations including absolute and relative evaluation systems. In particular, considering that the relative evaluation system approach can lead to intense competition and related psychological conflicts that undermine the cooperative atmosphere among students, the possibilities for applying the POD model in traditional classes need to be explored.

\section{Funding}

This research was supported by the Ministry of Education of the Republic of Korea and the National Research Foundation of Korea (NRF-2019S1A5C2A04081101).

\section{References}

Adedoyin, O. B., \& Soykan, E. (2020). Covid-19 pandemic and online learning: The challenges and opportunities. Interactive Learning Environments. https://doi.org/10.1080/10494820.2020.1813180

Ala, O. G., Yang, H., \& Ala, A. A. (2021). Leveraging integrated peer-assisted learning clusters as a support for online learning. Interactive Learning Environment. Advance online publication. https://doi.org/10.1080/10494820.2021.1943454

Alegre, F., Moliner, L., Maroto, A., \& Lorenzo-Valentin, G. (2020). Academic achievement and peer tutoring in mathematics: A comparison between primary and secondary education. SAGE Open, 10(2), 1-9. https://doi.org/10.1177/2158244020929295

Ali, A., \& Smith, D. (2015). Comparing social isolation effects on students' attrition in online versus face-to-face courses in computer literacy. Issues in Informing Science \& Information Technology, 12, 11-20. https://doi.org/10.28945/2258

Arco-Tirado, J. L., Fernández-Martín, F. D., \& Fernández-Balboa, J. M. (2011). The impact of a peer-tutoring program on quality standards in higher education. Higher Education, 62(6), 773-788. https://doi.org/10.1007/s10734-011-9419-x

Arco-Tirado, J. L., Fernández-Martín, F. D., \& Hervás-Torres, M. (2020). Evidence-based peer-tutoring program to improve students' performance at the university. Studies in Higher Education, 45(11), 2190-2202. https://doi.org/10.1080/03075079.2019.1597038

Atchley, W., Wingenbach, G., \& Akers, C. (2013). Comparison of course completion and student performance through online and traditional courses. International Review of Research in Open and Distance Learning, 14(4), 104-116. https://doi.org/10.19173/irrodl.v14i4.1461 
Cavus, N., Sani, A. S., Haruna, Y., \& Lawan, A. A. (2021). Efficacy of social networking sites for sustainable education in the era of COVID-19: A systematic review. Sustainability, 13(2), 808. https://doi.org/10.3390/su13020808

Cho, M. H., \& Heron, M. L. (2015). Self-regulated learning: The role of motivation, emotion, and use of learning strategies in students' learning experiences in a self-paced online mathematics course. Distance Education, 36(1), 80-99. https://doi.org/10.1080/01587919.2015.1019963

Comer, D., Baker, R., \& Wang, Y. (2015). Negativity in Massive Online Open Courses: Impacts on learning and teaching and how instructional teams may be able to address It. Insight: A Journal of Scholarly Teaching, 10, 92-113. https://doi.org/10.46504/10201508co

Dhawan, S. (2020). Online learning: A panacea in the time of COVID-19 crisis. Journal of Educational Technology, 49(1), 5-22. https://doi.org/10.1177/0047239520934018

De Backer, L., Van Keer, H., \& Valcke, M. (2015). Promoting university students' metacognitive regulation through peer learning: The potential of reciprocal peer tutoring. Higher Education, 70(3), 469-486. https://doi.org/10.1007/s10734-014-9849-3

Gemmell, I., \& Harrison, R. (2017). A comparison between national and transnational students' access of online learning support materials and experience of technical difficulties on a fully online distance learning master of public health programme. Open Learning: The Journal of Open, Distance and e-Learning, 32(1), 66-80. https://doi.org/10.1080/02680513.2016.1253463

Goodlad, S. (1998). Students as tutors and mentors. In S. Goodlad (Ed.), Mentoring and Tutoring by Students (pp. 1-17). Kogan Page Ltd.

Greenwood, C. (1997). Classwide peer tutoring. Behavior and Social Issues, 7(1), 53-57. https://doi.org/10.5210/bsi.v7i1.299

Jaggars, S. S. (2014). Choosing between online and face-to-face courses: Community college student voices. American Journal of Distance Education, 28(1), 27-38. https://doi.org/10.1080/08923647.2014.867697

Kaufmann, R., \& Vallade, J. I. (2020). Exploring connections in the online learning environment: Student perceptions of rapport, climate, and loneliness. Interactive Learning Environments, 1-15. https://doi.org/10.1080/10494820.2020.1749670

KOSIS. (2020, 2020-09-11). Number of postsecondary educational institutions. Korean Statistical Information Service. Retrieved April 30 from https://kosis.kr/statHtml/statHtml.do?orgId=101\&tblId=DT_1YL21181

Lee, Y., \& Choi, J. (2011). A review of online course dropout research: Implications for practice and future research. Educational Technology Research and Development, 59(5), https://doi.org/10.1007/s11423-010-9177-y

Lee, Y., Choi, J., \& Kim, T. (2013). Discriminating factors between completers of and dropouts from online learning courses. British Journal of Educational Technology, 44(2), 328-337 https://doi.org/10.1111/j.1467-8535.2012.01306.x

Mendoza, D. F., \& Kerl, E. (2021). Student perceived benefits of embedded online peer tutors. Learning Assistance Review (TLAR), 26(1), 53-73.

Moore, K., Bartkovich, J., Fetzner, M., \& Ison, S. (2003). Success in cyberspace: Student retention in online courses. Journal of Applied Research in the Community College, 10(2), 107-118. https://www.learntechlib.org/p/104016

Murphy, C. A., \& Stewart, J. C. (2017). On-campus students taking online courses: Factors associated with unsuccessful course completion. The Internet and Higher Education, 34, 1-9. https://doi.org/10.1016/j.iheduc.2017.03.001

Octaberlina, L. R., \& Muslimin, A. I. (2020). EFL students perspective towards online learning barriers and alternatives using Moodle/Google classroom during COVID-19. International Journal of Higher Education, 9(6), 1-9. https://doi.org/https://doi.org/10.5430/ijhe.v9n6p1

OECD. (2020). Education at a glance 2020: OECD Indicators. OECD Publishing.

Parkin, S., \& McKeganey, N. (2000). The rise and rise of peer education approaches. Drugs: Education, Prevention \& Policy, 7(3), 293-310. https://doi.org/10.1080/09687630050109961 
Patterson, B., \& McFadden, C. (2009). Attrition in online and campus degree programs. Online Journal of Distance Learning Administration, 12(2). https://www.westga.edu/ distance/ojdla/summer122/patterson112.html

Pevalin, D. J., \& Goldberg, D. P. (2003). Social precursors to onset and recovery from episodes of common mental illness. Psychological Medicine, 33(2), 299-306. https://doi.org/10.1017/S0033291702006864

Roscoe, R. D., \& Chi, M. T. H. (2007). Understanding tutor learning: Knowledge-building and knowledge-telling in peer tutors' explanations and questions. Review of Educational Research, 77(4), 534-574. https://doi.org/10.3102/0034654307309920

Sitzmann, T., Ely, K., Bell, B. S., \& Bauer, K. N. (2010). The effects of technical difficulties on learning and attrition during online training. Journal of Experimental Psychology: Applied, 16(3), 281-292. https://doi.org/10.1037/a0019968

Tew, J., Ramon, S., Slade, M., Bird, V., Melton, J., \& Le Boutillier, C. (2012). Social factors and recovery from mental health difficulties: A review of the evidence. British Journal of Social Work, 42(3), 443-460. https://doi.org/10.1093/bjsw/bcr076

Thurston, A., Cockerill, M., \& Chiang, T. H. (2021). Assessing the differential effects of peer tutoring for tutors and tutees. Education Sciences, 11(3), 97-108. https://doi.org/10.3390/educsci11030097

Thurston, A., Roseth, C., Chiang, T. H., Burns, V., \& Topping, K. J. (2020). The influence of social relationships on outcomes in mathematics when using peer tutoring in elementary school. International Journal of Educational Research Open, 1, 1-8. https://doi.org/10.1016/j.ijedro.2020.100004

Willging, P. A., \& Johnson, S. D. (2019). Factors that influence students' decision to dropout of online courses. Journal of Asynchronous Learning Networks, 13(3), 115-127. https://doi.org/10.24059/olj.v13i3.1659

Wladis, C., Conway, K., \& Hachey, A. C. (2017). Using course-level factors as predictors of online course outcomes: A multi-level analysis at a US urban community college. Studies in Higher Education, 42(1), 184-200. https://doi.org/10.1080/03075079.2015.1045478

Xu, Y., Hartman, S., Uribe, G., \& Mencke, R. (2001). The effects of peer tutoring on undergraduate students' final examination scores in mathematics. Journal of College Reading and Learning, 32(1), 22-31. https://doi.org/10.1080/10790195.2001.10850123

\section{Copyrights}

Copyright for this article is retained by the author(s), with first publication rights granted to the journal.

This is an open-access article distributed under the terms and conditions of the Creative Commons Attribution license (http://creativecommons.org/licenses/by/4.0/). 